Article

\title{
Tougher targets for China's clean air cities? Implications from air quality assessment in Shenzhen
}

\author{
Dian Huang1, 2 , Qinglan $\mathrm{Li}^{2},{ }^{*}$, Guangxin $\mathrm{Li}^{2}$, Xiaoxue Wang', and Liqun $\mathrm{Sun}^{2}$ \\ 1 College of Urban and Environmental Sciences, and Key Laboratory for Earth Surface Processes of the \\ Ministry of Education, Peking University, Beijing, 100871, China; E-Mail: huangdian@pku.edu.cn (D. H.) \\ 2 Shenzhen Institute of Advanced Technology, Chinese Academy of Sciences, Shenzhen, 518055, China; E- \\ Mails: q1.li@siat.ac.cn (Q. L.); ligx@siat.ac.cn (G. L.); xx.wang@siat.ac.cn (X.W.); lq.sun@siat.ac.cn (L. S.) \\ * Correspondence: q1.li@siat.ac.cn; Tel.: +86-131-2889-0309
}

\begin{abstract}
Shenzhen is China's top ten clean air city and the cleanest air megacity. Even so, epidemiologic studies have shown ambient air pollution had significant adverse impacts on human health in this less polluted city. In this study, the concentrations of six criteria air pollutants ( $\mathrm{PM}_{2.5}$, $\mathrm{PM}_{10}, \mathrm{O}_{3}, \mathrm{NO}_{2}, \mathrm{SO}_{2}$, and $\mathrm{CO}$ ) from 2014 to 2017 were analyzed and compared to thresholds of both national and international air quality standards. The results showed concentrations of all air pollutants were below target values of current national air quality standard, but levels of particulate matter (PM) and $\mathrm{O}_{3}$ were still much higher than the recommended levels by the World Health Organization. Within national air quality standards, the number of over-limit days was rare with few variations between highly polluted and low pollution areas. The air quality improvement was slowing down recently. Our results suggest annual and daily thresholds for PM are too loose for air quality improvement in Shenzhen. Hence, we call for evaluation and establishment of tougher air quality standard.
\end{abstract}

Keywords: air pollution; air quality standard; spatial pattern; variability; human health protection

\section{Introduction}

Although China's rapid economic growth and urbanization process have reduced the proportion of people living in poverty from 1981 to 2004 from $64 \%$ to $10 \%$ [1], increasing energy consumption and emissions of air pollutants from burning fossil fuels have produced widespread air pollution issues, especially in large cities [2-6]. Degradation of air quality is associated with increased mortality and morbidity as well as health damage to ecosystems [7, 8]. More than one-third of the Chinese population suffers from unhealthy air, killing about 1.6 million people each year [9]. Economic losses related to air pollution are equivalent to $\$ 112$ billion in 2005 [4]. Deterioration of air quality has hindered the sustainable development of China's economy [10].

Air quality standard was developed by the Ministry of Environmental Protection of China (renamed as the Ministry of Ecological Environment of China (MEE)) to tackle air pollution. China's ambient air quality standard GB 3095 was formulated in 1982, revised and introduced PM10 in 1996, tightened in 2000, and most recently amended and included PM2.5 in 2012 [11]. The latest GB 30952012 defines two levels of concentration thresholds. Grade-I is tight and applied in less populated areas such as nature reserves, scenic spots, and other protected areas. Grade-II is loose and used in more populated areas such as residential, mixed commercial and traffic areas, cultural/industrial, urban and surrounding rural areas. Correspondingly, China's air quality index (AQI) system is used to inform urban residents about air pollution status and its impacts on health every day, referencing 
higher pollution thresholds than the United States AQI system [12]. In order to achieve true 'clean' and 'safe' air, China will have to adopt stricter air quality standard sooner or later, preferably earlier.

Shenzhen was set up as China's first Special Economic Zone (SEZ) in 1980 and developed from a small fishing village to a megacity in less than three decades. Since vehicles are a major emission source in cities, great efforts have been made in controlling traffic emissions by transportation energy reform $[13,14]$. Shenzhen became the world's first city to electrify $100 \%$ of public buses at the end of 2017 and will electrify all taxis by the end of 2020 [15]. Government policies also prompt the popularity of clean fuel vehicles such as gasoline, hybrids, and electric vehicles [16]. According to China's annual air quality report from 2014 to 2017, Shenzhen is China's top ten clean air city and the cleanest air megacity [17], paradoxically, epidemiologic studies showed significant adverse health effects associated with air pollution [18-22].

The objective of this work was to investigate the air pollution situation in Shenzhen by comparing air pollutant concentrations to both national and international air quality standards. The spatial pattern and interannual variability of air pollution from 2014 to 2017 were analyzed for similarities and differences with regard to different air quality standards. From the perspective of human health protection and effective air quality management, the possibility of adopting more stringent air quality standard in Shenzhen was discussed.

\section{Materials and Methods}

\subsection{Study area and sites}

Shenzhen $\left(113^{\circ} 46^{\prime}-114^{\circ} 37^{\prime} \mathrm{E} ; 2^{\circ} 27^{\prime}-22^{\circ} 52^{\prime} \mathrm{N}\right)$ is located immediately north of Hong Kong and has a subtropical oceanic climate with an administrative area of $1997.27 \mathrm{~km}^{2}$ (see Figure 1). China's first special economic zone (SEZ) was set up in Shenzhen in 1980, covering only four districts (Luohu, Futian, Nanshan, and Yantian). As shown in Figure 1, the area of the original SEZ is located within the yellow border then extended to the entire city boundary in 2010. For the convenience of analysis, the other six districts (Bao'an, Longgang, Longhua, Guangming, Pingshan, and Dapeng) outside the original SEZ are called non-special economic zone (non-SEZ).

Shenzhen introduced GB 3095-2012 in 2013. Hourly concentrations of particulate matter (PM) with a diameter $<2.5 \mu \mathrm{m}\left(\mathrm{PM}_{2.5}\right)$ and $<10 \mu \mathrm{m}(\mathrm{PM} 10)$, ozone $\left(\mathrm{O}_{3}\right)$, nitrogen dioxide $\left(\mathrm{NO}_{2}\right)$, sulfur dioxide $\left(\mathrm{SO}_{2}\right)$, and carbon monoxide (CO) from 2014 to 2017 were provided by the China National and Shenzhen Environmental Monitoring Center. Figure 1 illustrates the locations of the 19 fixed monitoring stations. Details of information of each air quality monitoring site were listed in Table $\mathbf{1 .}$ According to the technical regulation of selection of ambient air quality monitoring stations $(\mathrm{HJ}$ 664-2013), urban assessing stations are set up for the purpose of monitoring the overall and changing trends of urban air quality. The location should not be near traffic intersections or major industrial sources of pollution, and should also be kept at an adequate distance from any other emitting sources. 

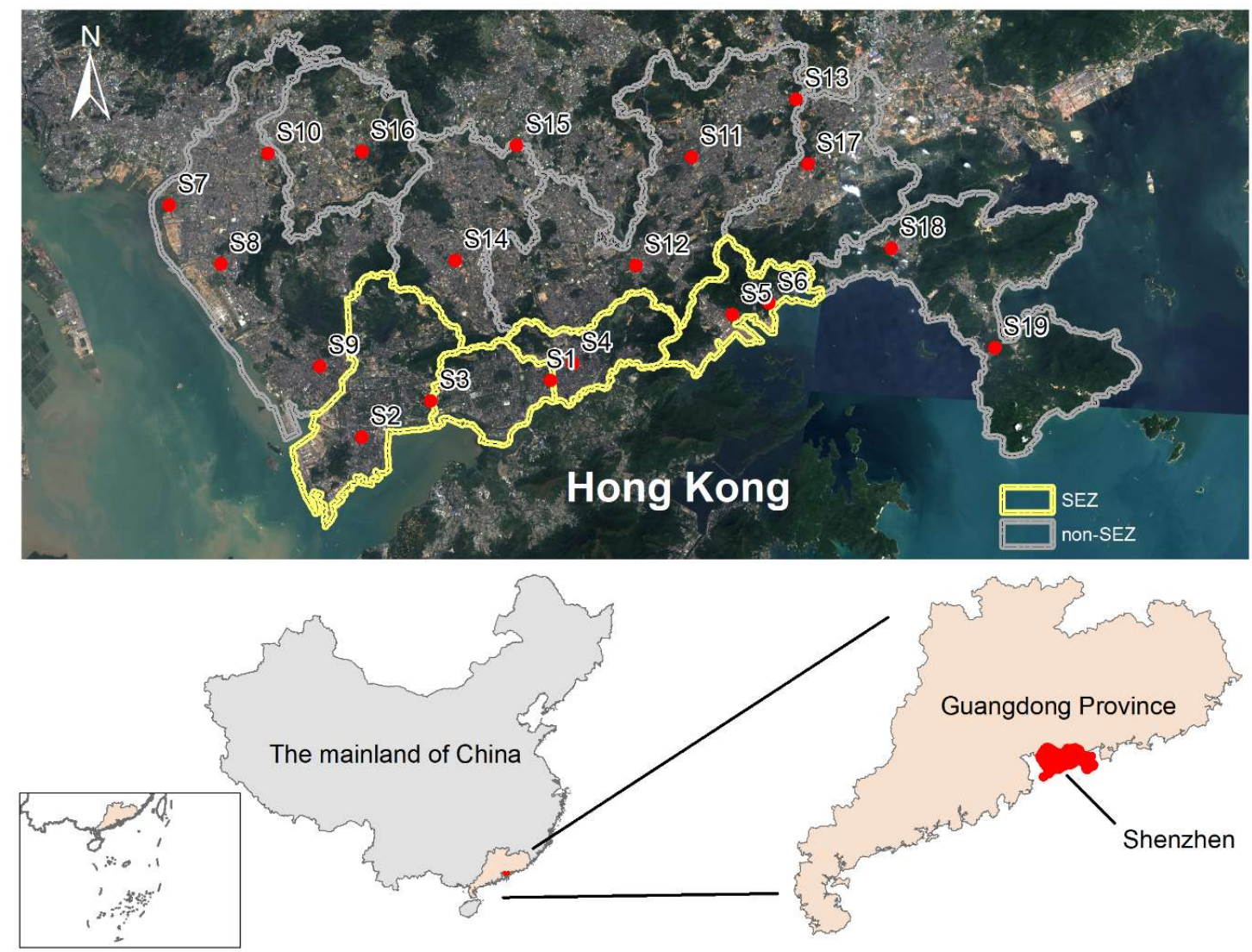

Figure 1. Location of the 19 automatic ambient air quality monitoring stations in Shenzhen. The yellow border is the original range of the special economic zone (SEZ) established in 1980. The area inside the grey boundary is referred to non-special economic zone (non-SEZ).

Table 1. Details of the 19 automatic ambient air monitoring stations in Shenzhen.

\begin{tabular}{ccccccccccc}
\hline $\begin{array}{c}\text { Site } \\
\text { Code }\end{array}$ & $\begin{array}{c}\text { Latitude } \\
\left({ }^{(} \mathbf{N}\right)\end{array}$ & $\begin{array}{c}\text { Longitude } \\
\left.\mathbf{(}{ }^{\circ} \mathbf{E}\right)\end{array}$ & District & Divisions & Region & \multicolumn{4}{c}{ Validity Data Rates $\mathbf{\%}(\mathbf{2 0 1 4 - 2 0 1 7})$} \\
\hline S1 & 22.5500 & 114.0958 & Futian & SEZ & 95.8 & 93.1 & 95.2 & 95 & 94.8 & 94.7 \\
S2 & 22.5167 & 113.9231 & Nanshan & SEZ & 96.3 & 95.3 & 96.1 & 96.3 & 96.2 & 96.1 \\
S3 & 22.5417 & 113.9872 & Nanshan & SEZ & 94.9 & 92.8 & 94.5 & 94.9 & 94.8 & 94.5 \\
S4 & 22.5625 & 114.1167 & Luohu & SEZ & 95.9 & 92.8 & 95.1 & 95.3 & 95.1 & 95.3 \\
S5 & 22.5908 & 114.2631 & Yantian & SEZ & 95 & 94.1 & 94.9 & 95.2 & 95.1 & 94.8 \\
S6 & 22.5978 & 114.2967 & Yantian & SEZ & 96.1 & 93.9 & 95.7 & 96.1 & 96.1 & 95.2 \\
S7 & 22.7261 & 113.7694 & Bao'an & Non-SEZ & 89.8 & 89 & 88.3 & 87.6 & 88.6 & 88.7 \\
S8 & 22.6728 & 113.8111 & Bao'an & Non-SEZ & 89.7 & 89.1 & 87.9 & 87.4 & 88.2 & 88.2 \\
S9 & 22.5794 & 113.8911 & Bao'an & Non-SEZ & 95.3 & 94.2 & 94.7 & 94.9 & 94.9 & 94.7 \\
S10 & 22.7622 & 113.8619 & Bao'an & Non-SEZ & 89.1 & 88.4 & 87.4 & 86.8 & 87.3 & 87.9 \\
S11 & 22.7267 & 114.2400 & Longgang & Non-SEZ & 96.6 & 94.7 & 96.6 & 96.6 & 96.6 & 96.2 \\
S12 & 22.6400 & 114.1814 & Longgang & Non-SEZ & 89.8 & 89.5 & 88.1 & 87.5 & 87.7 & 87.9 \\
S13 & 22.7667 & 114.3378 & Longgang & Non-SEZ & 86.7 & 85.2 & 85.3 & 84.9 & 85.1 & 85.4 \\
S14 & 22.6581 & 114.0206 & Longhua & Non-SEZ & 27.9 & 27.9 & 27.8 & 27.8 & 27.9 & 27.9 \\
S15 & 22.7500 & 114.0847 & Longhua & Non-SEZ & 95.1 & 94.4 & 93.7 & 93.4 & 94 & 94.3 \\
S16 & 22.7567 & 113.9461 & Guangming & Non-SEZ & 89.3 & 88.7 & 87.5 & 86.8 & 87.1 & 87.5 \\
S17 & 22.7117 & 114.3433 & Pingshan & Non-SEZ & 89.1 & 88.8 & 87.7 & 87.2 & 87.7 & 87.8 \\
S18 & 22.6342 & 114.4103 & Dapeng & Non-SEZ & 95 & 93.3 & 94.2 & 94.8 & 94.5 & 94.4 \\
S19 & 22.5422 & 114.4939 & Dapeng & Non-SEZ & 95 & 94.1 & 94.9 & 95 & 95 & 94 \\
\hline
\end{tabular}

\subsection{Methods}


Kolmogorov-Smirnov test, histogram plot, and Q-Q plot were used to examine the normality of air pollutant records. The results showed that most of the air pollutants were not normally distributed. Therefore, most of our statistical analyses were based on nonparametric methods. Hourly data were summarized as $8-\mathrm{h}$, daily, and annual concentrations. Only sites with more than $75 \%$ of the possible hours were included in the analysis. R software was used to perform statistical analyses and plot the figures $[23,24]$.

The concentration thresholds of multiple air quality standards were listed in Table 2 . The current national air quality standard for air quality regulation in urban areas is Grade-II of Chinese Air Quality Standards (CAAQS). Grade-I of CAAQS, European Union air quality standard (EUAQS), interim target-2 (IT2) and target-3 (IT3), and air quality guideline (AQG) of the World Health Organization (WHO) were also used for comparison [7-8, 25]. The WHO interim target- 1 had the same daily and annual thresholds for PM2.5, PM10, and $\mathrm{O}_{3}$ as the Grade-II of CAAQS so was not listed in Table 2. With the exception of $\mathrm{O}_{3}$ and $\mathrm{CO}$ thresholds, which are only on the hourly and daily basis, most air pollutants have both annual and daily limits for measuring exceedances of air quality standards. According to technical regulations of China's environmental air quality assessment (HJ 663-2013), the annual $\mathrm{O}_{3}$ and $\mathrm{CO}$ levels are represented by the $90^{\text {th }}$ percentile of the daily maximum 8-h average and $95^{\text {th }}$ percentile of the daily 24 -h average and reference the daily thresholds.

Table 2. Summary of concentration thresholds for different air quality standards. The units for $\mathrm{PM}_{2.5}, \mathrm{PM}_{10}, \mathrm{O}_{3}$, $\mathrm{NO}_{2}$, and $\mathrm{SO}_{2}$ are $\mu \mathrm{g} / \mathrm{m}^{3}$, where for $\mathrm{CO}$ is $\mathrm{mg} / \mathrm{m}^{3}$.

\begin{tabular}{cccccccc}
\hline $\begin{array}{c}\text { Air } \\
\text { pollutants }\end{array}$ & $\begin{array}{c}\text { Average } \\
\text { Time }\end{array}$ & $\begin{array}{c}\text { CAAQS } \\
\text { Grade-I }\end{array}$ & $\begin{array}{c}\text { CAAQS } \\
\text { Grade-II }\end{array}$ & $\begin{array}{c}\text { WHO } \\
\text { IT2 }\end{array}$ & $\begin{array}{c}\text { EU } \\
\text { AQS }\end{array}$ & $\begin{array}{c}\text { WHO } \\
\text { IT3 }\end{array}$ & $\begin{array}{c}\text { WHO } \\
\text { AQG }\end{array}$ \\
\hline \multirow{2}{*}{ PM$_{2.5}$} & $24-h$ & 35 & 75 & 50 & - & 37.5 & 25 \\
& $1-y$ & 15 & 35 & 25 & 25 & 15 & 10 \\
$\mathrm{PM}_{10}$ & $24-\mathrm{h}$ & 50 & 150 & 100 & $50(35)^{*}$ & 75 & 50 \\
& $1-\mathrm{y}$ & 40 & 70 & 50 & 40 & 30 & 20 \\
$\mathrm{O}_{3}$ & $1-\mathrm{h}$ & 160 & 200 & - & - & - & - \\
& $8-\mathrm{h}$ & 100 & 160 & - & $120(25)^{*}$ & - & 100 \\
$\mathrm{NO}_{2}$ & $1-\mathrm{h}$ & 200 & 200 & - & $200(18)^{*}$ & - & 200 \\
& $24-\mathrm{h}$ & 80 & 80 & - & - & - & - \\
& $1-\mathrm{y}$ & 40 & 40 & - & 40 & - & 40 \\
$\mathrm{SO}_{2}$ & $1-\mathrm{h}$ & 150 & 500 & - & $350(24)^{*}$ & - & - \\
& $24-\mathrm{h}$ & 50 & 150 & 50 & $125(3)^{*}$ & - & 20 \\
& $1-\mathrm{y}$ & 20 & 60 & - & - & - & - \\
$\mathrm{CO}^{*}$ & $1-\mathrm{h}$ & 10 & 10 & - & - & - & - \\
& $8-\mathrm{h}$ & - & - & - & 10 & - & - \\
& $24-\mathrm{h}$ & 4 & 4 & - & - & - & - \\
\hline
\end{tabular}

*Number inside the brackets are the permitted exceedances (days/hours) each year by EUAQS.

\section{Results and discussion}

\subsection{Spatial variations of air pollutants}

The annual concentrations of $\mathrm{PM}_{2.5}, \mathrm{PM}_{10}, \mathrm{O}_{3}, \mathrm{NO}_{2}, \mathrm{SO}_{2}$, and $\mathrm{CO}$ in each district of Shenzhen were summarized in Figure 2. The concentration of air pollutants varied significantly by districts (KruskalWallis, $p<0.05$ ) except for $\mathrm{CO}$. $\mathrm{PM}_{2.5}, \mathrm{PM}_{10}, \mathrm{O}_{3}$, and $\mathrm{SO}_{2}$ concentrations were significantly higher in non-SEZ than SEZ districts (Wilcoxon, $p<0.05$ ). The mean concentrations of most air pollutants in all SEZ districts were always below annual limits of national Grade-II standard except for $\mathrm{NO}_{2}$ which were above national limits in Nanshan and Luohu. For most non-SEZ districts, the mean concentrations of $\mathrm{PM}_{2.5}$ and $\mathrm{O}_{3}$ were high and above national targets. Dapeng was an exception with 
the lowest concentration of air pollutants. Besides that, $\mathrm{PM}_{10}, \mathrm{NO}_{2}, \mathrm{SO}_{2}$, and $\mathrm{CO}$ were generally below national limits. The concentrations of $\mathrm{PM}$ and $\mathrm{O}_{3}$ were close to the limits of EUAQS in Yantian and Dapeng but much higher than recommended levels by WHOAQG in all districts. Details of concentrations of each air pollutant at each site were shown in Table A1.

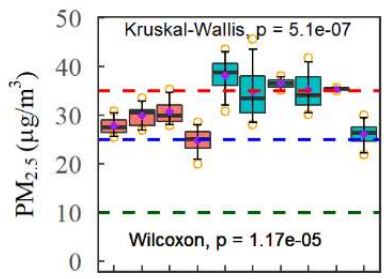

(a)

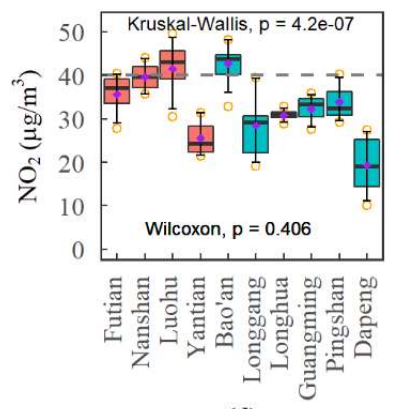

(d)

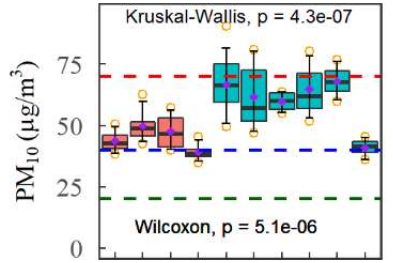

(b)

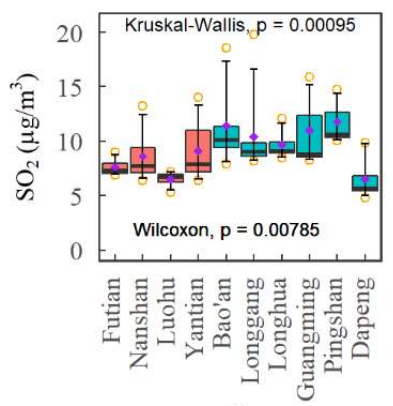

(e)

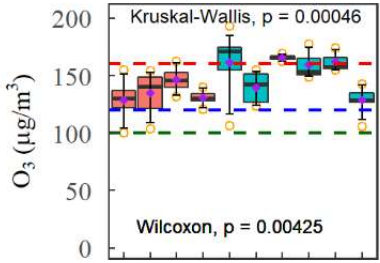

(c)

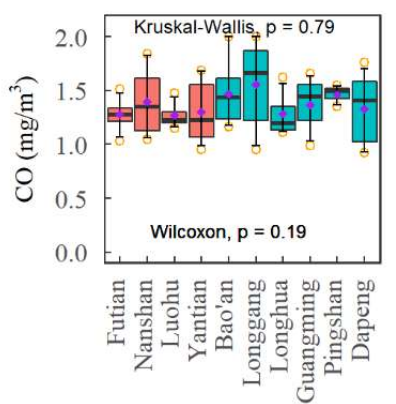

(f)

Figure 2. The annual concentrations of (a) $\mathrm{PM}_{2.5}$, (b) $\mathrm{PM}_{10}$, (c) $\mathrm{O}_{3}$, (d) $\mathrm{NO}_{2}$, (e) $\mathrm{SO}_{2}$, and (f) $\mathrm{CO}$ in each district of Shenzhen from 2014 to 2017. The horizontal solid lines indicate the median and the filled purple diamonds indicate the annual mean concentrations and range where the top and bottom of the box indicate the $75^{\text {th }}$ and $25^{\text {th }}$ percentiles, respectively. The top and bottom whiskers indicated the $95^{\text {th }}$ and $5^{\text {th }}$ percentile, and the orange circle indicated the maximum and minimum values, respectively. The horizontal red, blue, and green dashed lines represent the annual thresholds specified by CAAQS Grade-II, EUAQS, and WHOAQG. The gray dashed line indicates the same $\mathrm{NO}_{2}$ limits defined by different standards. The districts are grouped into SEZ and nonSEZ and ordered by a descending population size. Comparisons between SEZ and non-SEZ were performed by Wilcoxon sum-rank test. Difference between districts was compared through the Kruskal-Wallis test.

The exceeding rates for the four major air pollutants $\left(\mathrm{PM}_{2.5}, \mathrm{PM}_{10}, \mathrm{O}_{3}\right.$, and $\left.\mathrm{NO}_{2}\right)$ were presented in Figure 3. The exceeding rates were rare for all air pollutants in all districts based on daily limits of national air quality standard, the highest exceeding rate for $\mathrm{PM}_{2.5}$ was $7.2 \%$ in Bao' an. The highest exceeding rate for $\mathrm{PM}_{10}$ was $3.9 \%$ in Pingshan. Within this standard, no violated days were found for $\mathrm{PM}_{10}$ in Yantian and Dapeng. The exceeding rates for $\mathrm{O}_{3}$ were generally higher than PM levels, and the highest rate was $13.1 \%$ in Longhua district. The daily limits for $\mathrm{NO}_{2}$ were only defined in CAAQS, the highest exceeding rate was in Bao' an of 5.3\%. Dapeng, Yantian, and Longgang were all $<1 \%$.

The exceeding rates were much higher under other air quality standards. More detailed daily limits for PM control were defined by WHO interim target-2 and target-3. As for WHOIT2, the exceeding rates were all higher than national Grade-II. The exceeding rates for $\mathrm{PM}_{2.5}$ were also highest in Bao'an of 26\% and highest in Pingshan of 19\% for PM10. As for WHOIT3, the exceeding rates for PM2.5 and PM10 were both highest in Bao' an of 45\% and 38\%, respectively. The number of exceedances was above-permitted exceedances of EUAQS in all districts. Air pollution status was worst under WHOAQG, especially for PM pollution. Seven districts had $>50 \%$ of days per year exceeding the 
annual limits for $\mathrm{PM}_{2.5}$ of which Longhua had the highest of over 70\%. Five districts had $>50 \%$ of exceeding rates with the highest in Pingshan of $65 \%$. As for $\mathrm{O}_{3}$, the exceeding rates varied from $26 \%$ to $46 \%$ with the highest in Longhua.

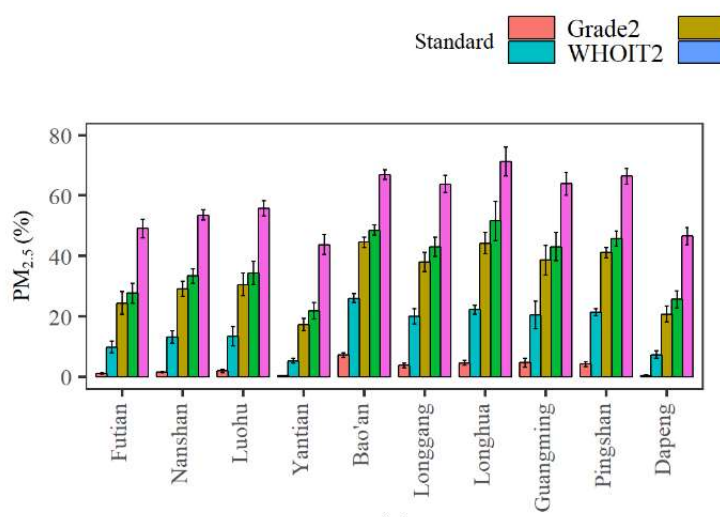

(a)

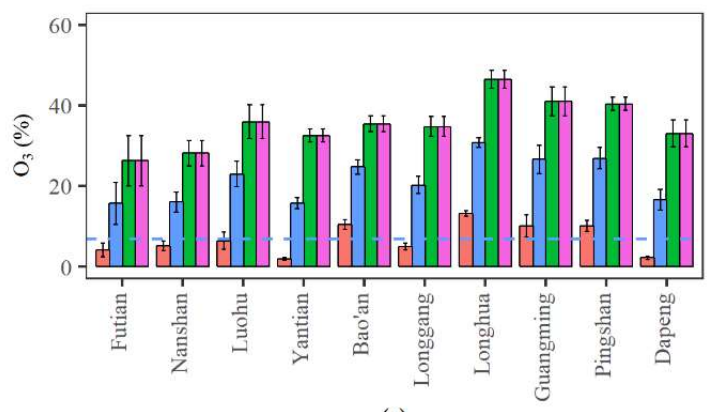

(c)

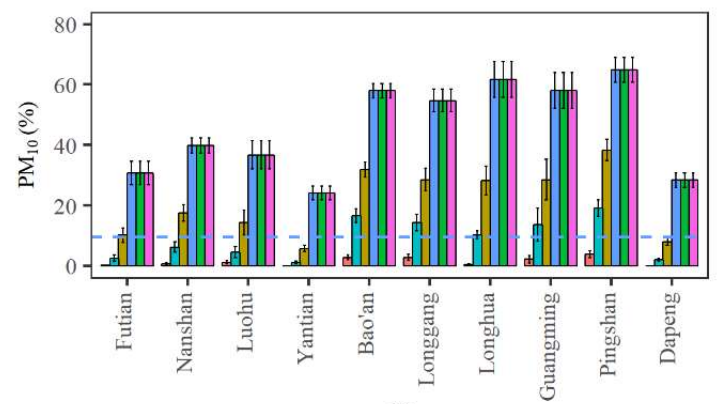

(b)

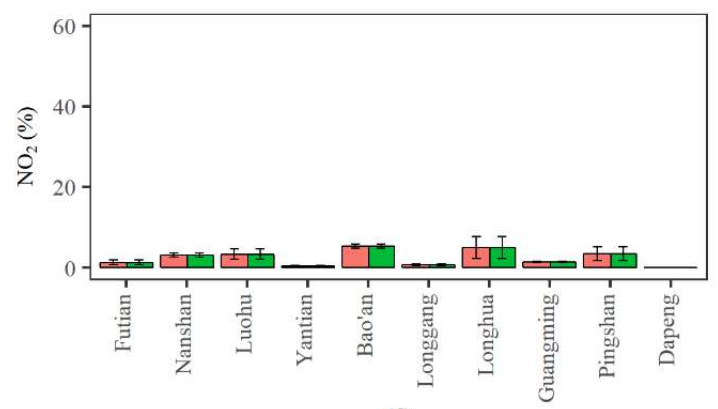

(d)

Figure 3. Average exceeding rates for the major air pollutants (a) $\mathrm{PM}_{2.5}$, (b) $\mathrm{PM}_{10}$, (c) $\mathrm{O}_{3}$, and (d) $\mathrm{NO}_{2}$ with regard to CAAQS Grade-I and Grade-II, EUAQS, IT2 and IT3, and AQG of WHO. The blue dashed lines are the permitted exceedances of EUAQS for $\mathrm{PM}_{10}$ and $\mathrm{O}_{3}$ respectively.

\subsection{Interannual variations of air pollutions}

Limited by the length of the observation period, the variations of air pollutants over time were made by Wilcoxon signed-rank test by comparing observations from consecutive monitoring stations between any two years (see Table A1). As shown in Figure 4, the concentration of PM2.5 was highest in 2014 and significantly lowered throughout the study period except for insignificant changes from 2016 to 2017. Similarly, the concentration of PM10 was also highest in 2014 and decreased significantly from 2014 to 2016 but then increased significantly from 2016 to 2017. However, O3 showed an opposite pattern of increasing over time and the highest year appeared in 2017 when $\mathrm{NO}_{2}$ was the lowest. In addition, the concentrations of $\mathrm{CO}$ were consistently lowered through time $(p<0.05)$, while the changes of $\mathrm{SO}_{2}$ was insignificant $(p>0.05)$. 


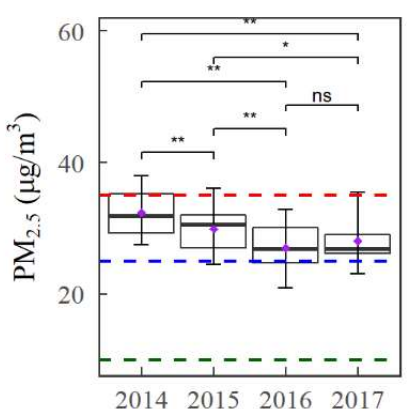

(a)

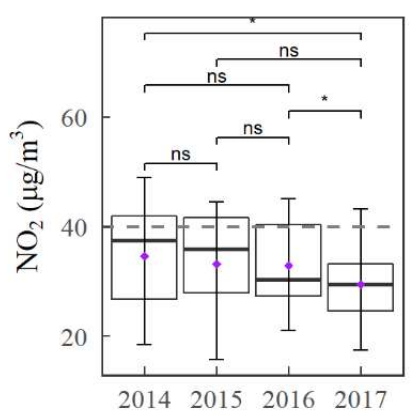

(d)

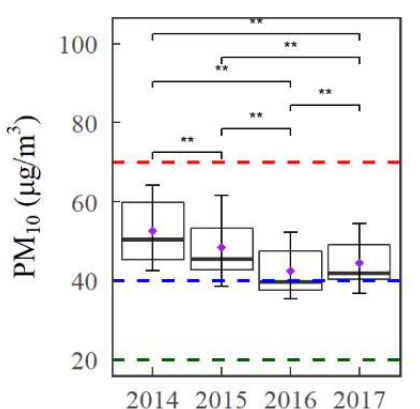

(b)

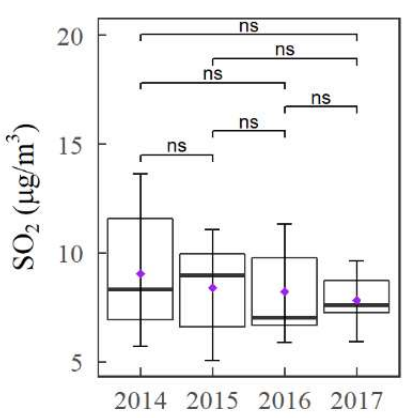

(e)

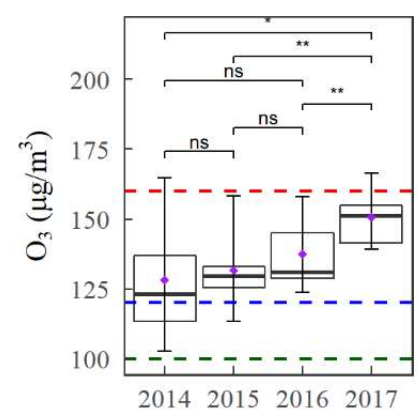

(c)

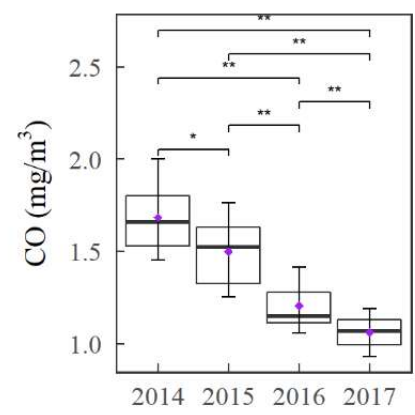

(f)

Figure 4. The annual concentrations of (a) $\mathrm{PM}_{2.5}$, (b) $\mathrm{PM}_{10}$, (c) $\mathrm{O}_{3}$, (d) $\mathrm{NO}_{2}$, (e) $\mathrm{SO}_{2}$, and (f) $\mathrm{CO}$ of consecutive monitoring stations in each year from 2014 to 2017. The horizontal solid lines indicate the median and the filled purple diamonds indicate the annual mean concentrations and range where the top and bottom of the box indicate the $75^{\text {th }}$ and $25^{\text {th }}$ percentiles, respectively. The top and bottom whiskers indicated the $95^{\text {th }}$ and $5^{\text {th }}$ percentile. Comparisons between years were made by Wilcoxon signed-rank test. ns, ${ }^{*}$, and ${ }^{* *}$ refer to statistical difference at significant level of $p>0.05, p<0.05, p<0.01$.

\subsection{Air Pollutants Exceeding Standard Levels}

The arithmetic means and number of annual over-limit days of $\mathrm{PM}_{2.5}, \mathrm{PM}_{10}, \mathrm{O}_{3}, \mathrm{NO}_{2}, \mathrm{SO}_{2}$, and $\mathrm{CO}$ under different air quality standards were shown in Table 3. The air pollution status was less severe under current national air quality standard. All air pollutants were below annual limits and the over-limit days were rare. $\mathrm{O}_{3}$ had the most number of over-limit days of 24 days per year which is slightly more than other air pollutants. For all other air quality standards which had tougher limits for $\mathrm{PM}$ and $\mathrm{O}_{3}$, the over-limit days were greatly elevated. The number of over-limit days were most under WHOAQG with about 215, 170, and 128 days per year failed to meet the target value for PM2.5, $\mathrm{PM}_{10}$, and $\mathrm{O}_{3}$, respectively.

Table 3. Average concentrations and number of annual over-limit days under different air quality standards.

The units for average concentrations of $\mathrm{PM}_{2.5}, \mathrm{PM}_{10}, \mathrm{O}_{3}, \mathrm{NO}_{2}$, and $\mathrm{SO}_{2}$ are $\mu \mathrm{g} / \mathrm{m}^{3}$, where for $\mathrm{CO}$ is $\mathrm{mg} / \mathrm{m}^{3}$.

\begin{tabular}{cccccccc}
\hline Variable & Average & $\begin{array}{c}\text { CAAQS } \\
\text { Grade-II }\end{array}$ & $\begin{array}{c}\text { WHO } \\
\text { IT2 }\end{array}$ & $\begin{array}{c}\text { WHO } \\
\text { IT3 }\end{array}$ & $\begin{array}{c}\text { EU } \\
\text { AQS }\end{array}$ & $\begin{array}{c}\text { CAAQS } \\
\text { Grade-I }\end{array}$ & $\begin{array}{c}\text { WHO } \\
\text { AQG }\end{array}$ \\
\hline $\mathrm{PM}_{2.5}$ & 32 & 14 & 62 & 124 & - & 141 & 215 \\
$\mathrm{PM}_{10}$ & 54 & 8 & 37 & 81 & 170 & 170 & 170 \\
$\mathrm{O}_{3}$ & 144 & 24 & - & - & 78 & 128 & 128 \\
$\mathrm{NO}_{2}$ & 33 & 11 & - & - & - & 11 & - \\
$\mathrm{SO}_{2}$ & 9.4 & 0 & 15 & - & 0 & 15 & 22 \\
$\mathrm{CO}$ & 1.4 & 2 & - & - & 2 & 2 & - \\
\hline
\end{tabular}


It is worth noting that, the over-limit days of $\mathrm{O}_{3}$ were more than $\mathrm{PM}_{2.5}$ and $\mathrm{PM}_{10}$ under national Grade-II but less under EUAQS and WHOAQG, indicating the current national air quality standard was loose in PM regulation. As shown in Figure 5, the concentrations of PM were much higher than the national target values in northern areas e.g., Beijing and the whole Jing-Jin-Ji (JJJ) area. Shanghai and the whole Yangtze River Delta Region (YRD) had lower levels of air pollutants than northern cities. The Pearl River Delta region (PRD) is the most clean economic vibrant regions in China, the average concentrations of air pollutants were lower than JJJ and PRD regions. Guangzhou and Shenzhen were two megacities in PRD, the concentration of air pollutants in Shenzhen were lowest among all megacities and economically vibrant regions.

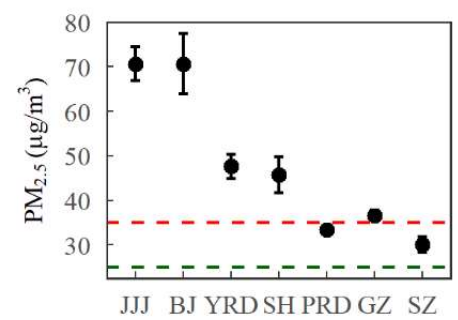

(a)

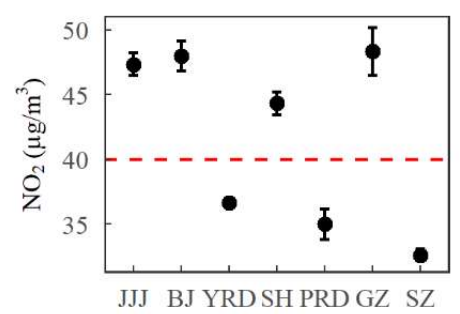

(d)

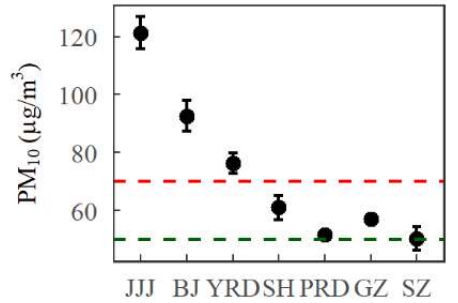

(b)

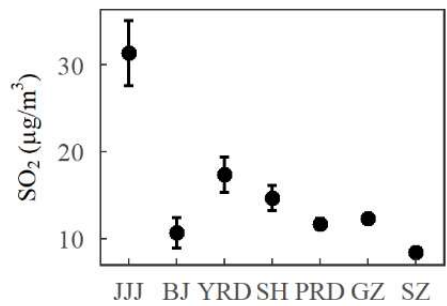

(e)

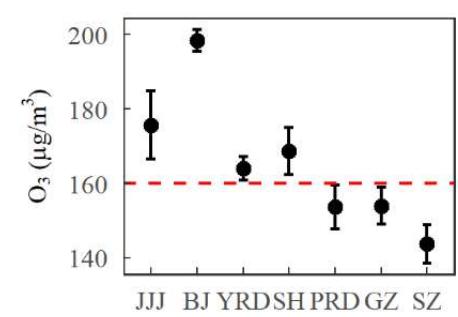

(c)

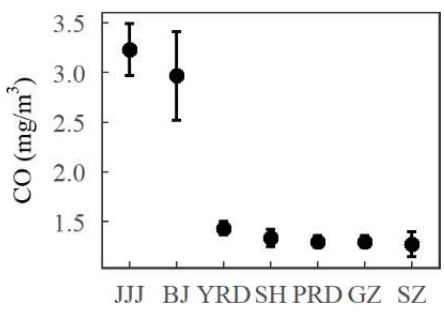

(f)

Figure 5. Annual mean concentrations of (a) $\mathrm{PM}_{2.5}$, (b) $\mathrm{PM}_{10}$, (c) $\mathrm{O}_{3}$, (d) $\mathrm{NO}_{2}$, (e) $\mathrm{SO}_{2}$, and (f) $\mathrm{CO}$ in China's economically vibrant regions and megacities from 2015 to 2017. Error bars represent standard error of the mean. JJJ: Jing-Jin-Ji, BJ: Beijing, YRD: Yangtze River Delta Region, SH: Shanghai, PRD: Pearl River Delta Region, GZ: Guangzhou, SZ: Shenzhen. The horizontal red dashed line represents the annual thresholds specified by CAAQS Grade-II. The green dashed line represents the thresholds of WHOIT2.

\section{Discussion}

The concentrations of most air pollutants showed spatial variations, indicating emission sources were unevenly distributed. The air quality in Yantian and Dapeng were better than other districts, possibly linked to their smaller population. Similar to previous studies, air pollution was mainly worse in non-SEZ districts [18, 26]. The higher concentrations of air pollutants in non-SEZ districts are probably caused by larger local emissions. Non-SEZ districts were designated to be the main industrial center of Shenzhen since the master plan of Shenzhen 1996-2010 [27]. Construction pollution is also a major source of PM emissions [28]. Recent rapid urbanization is mainly taking place in non-SEZ districts due to large areas of open land at a lower land price [27, 29]. In particular, Bao'an, the largest population district, newly increased areas of land were largely from reclaiming from the sea [29].

Traffic is a major source of $\mathrm{NO}_{2}$ emissions in urban areas [30]. Our results showed $\mathrm{NO}_{2}$ were generally higher in SEZ districts due to higher population and traffic density. Bao'an also had high 
$\mathrm{NO}_{2}$ concentrations which may be caused by its large pollution and its location adjacent to the SEZ districts. $\mathrm{NO}_{2}$ levels have been lowered over time, possibly linked to the traffic energy reform in Shenzhen and the national $\mathrm{NO}_{x}$ regulation measures [14-15, 31]. Meanwhile, $\mathrm{O}_{3}$ concentrations are increasing which are probably caused by lowered $\mathrm{NO}_{x}$ titration effects in a VOC limited urban environment. Great challenges remain in controlling $\mathrm{O}_{3}$ in Shenzhen [31].

The concentrations of all air pollutants in Shenzhen have met current national annual target values. The thresholds for $\mathrm{PM}$ and $\mathrm{O}_{3}$ of national air quality standard are inherited from WHO's interim target-1 (IT1). Those values are associated with about $15 \%$ of long-term mortality risk compared with the AQG level [7]. $\mathrm{PM}_{2.5}, \mathrm{PM}_{10}$, and $\mathrm{O}_{3}$ are still higher than annual limits of other tougher air quality standards except for the concentration of PM10 are very close to limit of WHOIT2, meaning that the risk for premature mortality has been lowered approximately $6 \%$ relative to IT1 level. In general, $\mathrm{PM}$ and $\mathrm{O}_{3}$ levels in Shenzhen are still not safe for human health which explains reported mortality and morbidity caused by air pollution in this less polluted city [18-22].

The daily limits of current national air quality standard for PM are too loose for efficient air quality management in Shenzhen. The number of over-limit days was rare under current national standards, especially for the PM. The few variations among districts indicate weak discrimination between highly and lowly polluted districts. The over-limit days were much more under other air quality standards, and the violation rates were much higher in the non-SEZ districts. The concentrations of most air pollutants have been lowered compared with values in the year 2014. The recent changes for $\mathrm{PM}_{2.5}$ were insignificant. The levels of $\mathrm{PM}_{10}$ were even slightly elevated from 2016 to 2017. This might be caused by lost of binding after meeting national air quality standards. In fact, those levels are still unhealthy for human health causing direct mortality/morbidity and indirect economic burden for China. From the perspective of more efficient air quality control, more stringent air quality standards are needed.

Our results have shown that Shenzhen's air quality is much better than China's other megacities and economically vibrant regions. Besides that, the concentrations of PM are also lower than other major cities in western and northwestern of China like Chengdu and Lanzhou [32, 33]. The annual target values for PM regulation have been greatly pulled up by China's heavily polluted cities and are lack of proper guidance for Shenzhen. As a matter of fact, the PM levels were comparable with cities in Poland and northern Italy [8]. The $\mathrm{PM}_{2.5}$ and $\mathrm{PM}_{10}$ levels of the two districts Yantian and Dapeng are already below or close to EU's reference line. Hence, EU's limits for PM regulation is practical reference value for air quality control in Shenzhen.

Air quality standard is vital in guiding air pollution controls. The status of nonattainment will put great pressure on local government to make more strict control measures in order to meet the target values. Great efforts have been made by the local government to control air pollutant emissions, it is a pioneer city in China's new energy reform with low carbon emission development strategy. In order to prompt air quality improvement progress and achieve real clean and safe air, attempts should be made to adopt more stringent air quality standards.

\section{Conclusions}

The key findings in this paper derive from the fact that Shenzhen is considered a less polluted city in China, paradoxically, research has reported significant adverse impacts of air pollution on human health. In order to present the air quality status in Shenzhen, the concentrations of air 
pollutants from 2014 to 2017 were analyzed and compared to both national and international air quality standards, as well as interim targets and guidelines by the World Health Organization.

Our results showed the average concentrations of air pollutants in Shenzhen have met China's annual target with rare exceedances. However, the concentrations of $\mathrm{PM}$ and $\mathrm{O}_{3}$ are still much higher than the limits of other air quality standards. According to air quality guidelines of WHO, PM2.5 is still the primary air pollutant in Shenzhen with the highest human health risks.

The daily and annual limits for PM of national air quality standard are too loose to guide air control in Shenzhen. In order to achieve real clean and safe air, more stringent air quality standard is needed in Shenzhen.

Author Contributions: Conceptualization, Dian Huang; Formal analysis, Dian Huang; Funding acquisition, Qinglan Li; Methodology, Dian Huang; Software, Guangxin Li; Supervision, Qinglan Li; Validation, Guangxin Li and Xiaoxue Wang; Visualization, Liqun Sun; Writing - original draft, Dian Huang; Writing - review \& editing, Qinglan Li.

Acknowledgments: The authors wish to thank all the staff in the Joint Engineering Research Center for Health Big Data Intelligent Analysis Technology. We also thank Shenzhen Discipline Construction Project for Urban Computing and Data Intelligence. This research was funded by the Innovation of Science and Technology Commission of Shenzhen Municipality with Grants JCYJ20170413164957461, and the National Natural Science Foundation of China with Grants 61433012 and U1435215.

Conflicts of Interest: The authors declare no conflict of interest.

\section{References}

1. Chen, S.; Ravallion, M. Absolute poverty measures for the developing world, 1981-2004. Proc. National Acad. Sci. 2007, 104, 16757-16762, doi: 10.1073/pnas.0702930104.

2. Chan, C.; Yao, X. Air pollution in mega cities in China. Atmos. Environ. 2008, 42, 1-42, doi: 10.1016/j.atmosenv.2007.09.003.

3. Kan, H.; Chen, R.; Tong, S. Ambient air pollution, climate change, and population health in China. Environ. Int. 2012, 42, 10-19, doi: 10.1016/j.envint.2011.03.003.

4. Matus, K.; Nam, K.-M.; Selin, N.; Lamsal, L.; Reilly, J.; Paltsev, S. Health damages from air pollution in China. Global Environ. Change 2012, 22, 55-66, DOI: 10.1016/j.gloenvcha.2011.08.006

5. Chen, Z.; Wang, J.-N.; Ma, G.-X.; Zhang, Y.-S. China tackles the health effects of air pollution. The Lancet 2013, 382, 1959-1960, doi: 10.1016/S0140-6736(13)62064-4.

6. Liu, M.; Huang, Y.; Ma, Z.; Jin, Z.; Liu, X.; Wang, H.; Liu, Y.; Wang, J.; Jantunen, M.; Bi, J.; Kinney, P. Spatial and temporal trends in the mortality burden of air pollution in China: 2004-2012. Environ. Int. 2017, 98, 7581, doi: 10.1016/j.envint.2016.10.003.

7. World Health Organization. Air quality guidelines for particulate matter, ozone, nitrogen oxide and sulfur dioxide - Global update, $2005 . \quad$ Available online: http://www.who.int/phe/health_topics/outdoorair/outdoorair_aqg/en/ (accessed on 20 September 2018).

8. EEA. Air quality in Europe - 2017 report; EEA Report No 11/2017; European Environment Agency, 2017. Available online: https://www.eea.europa.eu/publications/air-quality-in-europe-2017 (accessed 20 September 2018).

9. Rohde, R.; Muller, R. Air Pollution in China: Mapping of Concentrations and Sources. PLOS ONE 2015, 10, e0135749, doi: 10.1371/journal.pone.0135749.

10. He, C.; Pan, F.; Yan, Y. Is Economic Transition Harmful to China's Urban Environment? Evidence from Industrial Air Pollution in Chinese Cities. Urban Studies 2012, 49, 1767-1790, doi: 10.1177/0042098011415719.

11. Zhao, B.; Su, Y.; He, S.; Zhong, M.; Cui, G. Evolution and comparative assessment of ambient air quality standards in China. J. Integr. Environ. Sci. 2016, 13, 85-102, doi: 10.1080/1943815X.2016.1150301.

12. Hu, J.; Ying, Q.; Wang, Y.; Zhang, H. Characterizing multi-pollutant air pollution in China: Comparison of three air quality indices. Environ. Int. 2015, 84, 17-25, doi: 10.1016/j.envint.2015.06.014.

13. Fu, L.; Hao, J.; He, D.; He, K.; Li, P. Assessment of Vehicular Pollution in China. J. Air Waste Manage. 2001, 51, 658-668, doi: 10.1080/10473289.2001.10464300. 
14. Dong, D.; Duan, H.; Mao, R.; Song, Q.; Zuo, J.; Zhu, J.; Wang, G.; Hu, M.; Dong, B.; Liu, G. Towards a low carbon transition of urban public transport in megacities: A case study of Shenzhen, China. Resour. Conserv. Recy. 2018, 134, 149 - 155, doi: 10.1016/j.resconrec.2018.03.011.

15. Yang F.; Goldmann, M.; Lagercrantz, J. Sustainable mobility the Chinese way - opportunities for European cooperation and inspiration. Exakta Print: Malmö, Sweden 2018, 1 - 107, ISBN: 978-91-87379-45-1.

16. Wang, F.; Yu, J.; Yang, P.; Miao, L.; Ye, B. Analysis of the barriers to widespread adoption of electric vehicles in Shenzhen China. Sustainability 2017, 9, 522, doi: 10.3390/su9040522.

17. Ministry of Environmental Protection of the People's Republic of China. China environmental status bulletin from 2014 to 2017. Available online: http://www.mee.gov.cn/hjzl/zghjzkgb/lnzghjzkgb/ (accessed 20 September 2018 in Chinese).

18. Zhang, F.; Liu, X.; Zhou, L.; Yu, Y.; Wang, L.; Lu, J.; Wang, W.; Krafft, T. Spatiotemporal patterns of particulate matter (PM) and associations between PM and mortality in Shenzhen, China. BMC Public Health 2016, 16, 215, doi: 10.1186/s12889-016-2725-6.

19. Wu, Y.; Zhang, F.; Shi, Y.; Pilot, E.; Lin, L.; Fu, Y.; Krafft, T.; Wang, W. Spatiotemporal characteristics and health effects of air pollutants in Shenzhen. Atmos. Pollut. Res. 2016, 7, 58-65, doi: 10.1016/j.apr.2015.07.005

20. Xia, X.; Zhang, A.; Liang, S.; Qi, Q.; Jiang, L.; Ye, Y. The association between air pollution and population health risk for respiratory infection: A case study of Shenzhen, China. Int. J. Env. Res. Pub. He. 2017, 14, 950, doi: 10.3390/ijerph14090950.

21. Wang, L.; Bai, Y.; Zhang, F.; Wang, W.; Liu, X.; Krafft, T. Spatiotemporal Patterns of Ozone and Cardiovascular and Respiratory Disease Mortalities Due to Ozone in Shenzhen. Sustainability 2017, 9, 559, doi: 10.3390/su9040559.

22. Liu, Y.; Chen, S.; Xu, J.; Liu, X.; Wu, Y.; Zhou, L.; Cheng, J.; Ma, H.; Zheng, J.; Lin, D.; Zhang, L.; Chen, L. The association between air pollution and outpatient and inpatient visits in Shenzhen, China. Int. J. Env. Res. Pub. He. 2018, 15, 178, doi: 10.3390/ijerph15020178.

23. R Core Team (2018). R: A language and environment for statistical computing. $R$ foundation for statistical computing, Vienna, Austria. URL: https://www.R-project.org/.

24. H. Wickham. ggplot2: Elegant graphics for data analysis. Springer-Verlag New York, 2016.

25. European Union Air quality Standards. Available online: http://ec.europa.eu/environment/air/quality/standards.htm (accessed on 4 October 2018).

26. Xia, X.; Qi, Q.; Liang, H.; Zhang, A.; Jiang, L.; Ye, Y.; Liu, C.; Huang, Y. Pattern of Spatial Distribution and Temporal Variation of Atmospheric Pollutants during 2013 in Shenzhen, China. ISPRS Int. J. Geo-Inf. 2017, 6, 2, doi: 10.3390/ijgi6010002.

27. Huang, L.; Xie, Y. The plan-led urban form: A case study of Shenzhen. In $48^{\text {th }}$ ISOCARP Congress; 2012.

28. Muleski, G.; Jr., C.; Kinsey, J. Particulate Emissions from Construction Activities. J. Air Waste. Manage. 2005 55, 772-783, doi: 10.1080/10473289.2005.10464669

29. Dou, P.; Chen, Y. Dynamic monitoring of land-use/land-cover change and urban expansion in Shenzhen using Landsat imagery from 1988 to 2015. Int. J. Remote Sens. 2017, 38, 5388-5407, doi: 10.1080/01431161.2017.1339926.

30. Kuik, F.; Kerschbaumer, A.; Lauer, A.; Lupascu, A.; Schneidemesser, E. von; Butler, T. Top-down quantification of NOx emissions from traffic in an urban area using a high-resolution regional atmospheric chemistry model. Atmos. Chem. Phys. 2018, 18, 8203-8225, doi: 10.5194/acp-18-8203-2018

31. Huang D.; Li Q.; Sun L.; Li G.; Wang X.; He B.; Zhang L.; Zhang C. Spatial pattern and temporal trend of ambient ozone and its precursor nitrogen oxides from 2011 to 2017 in Shenzhen, China. Environ. Sci. Pollut. $R$. Under Review.

32. Xiao, K.; Wang, Y.; Wu, G.; Fu, B.; Zhu, Y. Spatiotemporal Characteristics of Air Pollutants (PM10, PM2.5, $\mathrm{SO}_{2}, \mathrm{NO}_{2}, \mathrm{O}_{3}$, and $\mathrm{CO}$ ) in the Inland Basin City of Chengdu, Southwest China. Atmosphere 2018, 9, 74, doi:10.3390/atmos9020074

33. Zhang, Y.; Cao, F. Fine particulate matter ( $\left.\mathrm{PM}_{2.5}\right)$ in China at a city level. Scientific Reports 2015, 5, doi: $10.1038 /$ srep14884. 